\title{
Wide Bandgap Based Modular Driving Techniques for Switched Reluctance Motor Drives
}

\author{
$1^{\text {st }}$ Abdalla Hussein Mohamed \\ Electromechanical, Systems and Metal Engineering \\ Ghent University \\ Flanders Make@UGent - corelab EEDT-MP \\ Cairo University \\ a.hussien.rashad@gmail.com
}

\author{
$2^{\text {nd }}$ Hendrik Vansompel \\ Electromechanical, Systems and Metal Engineering \\ Ghent University \\ Ghent, Belgium \\ Flanders Make@UGent - corelab EEDT-MP \\ Hendrik.Vansompel@UGent.be
}

\author{
$3^{\text {rd }}$ Ahmed Hemeida \\ EPE \\ Cairo University \\ Cairo, Egypt \\ a.hemeida@live.com
}

\author{
$4^{\text {th }}$ Peter Sergeant \\ Electromechanical, Systems and Metal Engineering \\ Ghent University \\ Ghent, Belgium \\ Flanders Make@UGent - corelabEEDT-MP \\ Peter.Sergeant@UGent.be
}

\begin{abstract}
In switched reluctance motors, the stator can be seen as comprising a stator yoke and a modular tooth-coil construction. Each module consists of a concentrated winding wound around a steel pole. In the conventional driving technique, depending on the number of the stator poles, a number of coils are connected together and driven from one asymmetric $\mathrm{H}$-bridge. Another possible driving technique is the modular one in which each stator coil is driven by a separate asymmetric H-bridge. In this way, the fault tolerance of the drive is highly enhanced. In this paper, three modular driving techniques are proposed, simulated and compared to the conventional one. The difference between the three modular techniques is in the number of turns per stator coil and the DC-link voltage compared to the conventional one. The first technique maintains both the number of turns per coil and the DC-link voltage, the second one maintains the number of turns per coil while halving the DC- link voltage and the last one maintains the DClink voltage and doubles the number of turns per coil. All the techniques are applied on a 6/4 SRM machine. The technique that maintains the DC-link voltage and doubles the number of turns shows superior performance in terms of the drive efficiency and the converter power density but results in the highest torque ripple. The technique that halves the DC-link voltage achieves a low torque ripple and an efficiency equal to the conventional technique. The converter is designed using $\mathrm{SiC}$ technology to enable higher switching frequency capability so that, a smaller DC-link capacitance can be obtained and a high drive efficiency as well.
\end{abstract}

Index Terms-Wide bandgap (WBG) devices, Modular Motor Drives, Switched Reluctance Motor (SRM) drives, Cooling, Torque ripple, Power density

\section{INTRODUCTION}

Switched reluctance motor (SRM) drives have a rugged and modular stator pole construction. The absence of the windings and the permanent magnets in the rotor makes the SRM machines more reliable and lighter compared to the other conventional machines [1]. The magnetic independance of the stator coils makes the SRM machines an excellent fault tolerant drives [2]. The airgap torque generated by this machine is proportional to the square of the coil current which makes them high starting torque machines which is an important feature for the traction applications. These excellent properties of the SRM machines make them attractive and competitive in applications like hybrid electric vehicles (HEVs) [3].

The main drawback of these machines is the high torque ripple and hence the vibration resulting from the discrete torque pulses generated by each coil. Different control techniques are existing in literature, the cascaded speed control loops and the direct torque control techniqes for torque ripple minmization [4].

Many converter topologies are existing in literature for controlling the SRM machine. The most commonly used converter due to its minimum passive components count is the asymmetric H-bridge.

In the conventional driving technique of the SRM machine, depending on the number of the stator poles, a group of stator coils are connected together to form one phase and driven from one asymmetric H-bridge. This driving technique has the advantage of minimum converter component count and DC-link capacitor size but less fault tolerant compared to the modular driving techniques.

Modular driving techniques enhance the fault tolerance of the whole drive. In [5], the authors proposed the modular driving technique in which the coil voltage and the number of turns per coil are kept the same as the conventional driving technique for integrated SRM drives.

In this paper, three modular driving techniques are studied and compared with the conventional one. These techniques are as follows: $\left(N_{s}, V_{d c}\right),\left(N_{s}, \frac{V_{d c}}{2}\right),\left(2 N_{s}, V_{d c}\right)$.

The drive efficiency, the torque ripples, the converter losses and cooling requirement and the DC-link capacitor size are all evaluated and compared for the four driving techniques, the conventional one and the modular ones.

The paper is divided as follows: section II is dedicated 


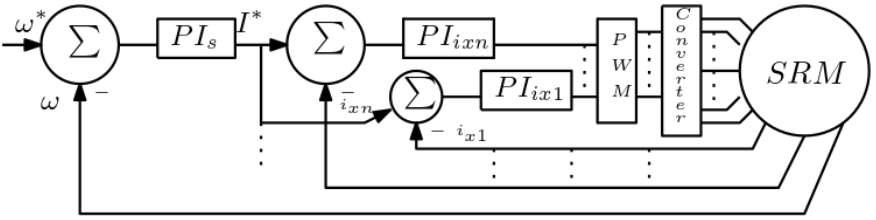

Fig. 1. A block diagram for the SRM drive

for the explanation of the dynamic and electromagnetic finite element modelling of the SRM machine for the four driving techniques, section III is dedicated for the investigation and comparison of the simulation results.

\section{Modelling OF SRM DRIVES}

Dynamic and physics based simulation models are crucial for the study of the SRM drives. Dynamic simulation models are necessary to predict the winding and the power electronics devices currents for certain closed loop control method.

Prediction of the winding and the power electronics devices current waveforms is indispensable for the estimation of the electromagnetic power losses of the machine and the losses in the power electronics devices.

The physics based simulation models such as the electromagnetic and the thermal finite element models (FEM) are necessary for the estimation of the machine core losses and the temperature.

A 6/4 SRM machine with the geometrical parameters and ratings in Table I is considered in this study.

\section{A. Dynamic simulation model}

The complete variable speed SRM drive system consists of three main subsystems: the switched reluctance machine, the power converter and the controller that regulates the speed and/or the torque. Fig. 1 shows a block diagram for the complete SRM drive system. The whole model is built using MATLAB/SIMULINK.

1) The SRM machine model: To make it possible to study the conventional and the modular driving techniques, each coil is modelled using (1)-(3).

TABLE I

THE KEY PARAMETERS OF THE 6/4 SRM CASE STUDY

\begin{tabular}{|c|c|c|}
\hline Parameter & Symbol & Value \\
\hline Stator outer diameter (mm) & $D_{s o}$ & 100 \\
Stator yoke thickness (mm) & $Y_{s t}$ & 9 \\
Rotor outer diameter (mm) & $D_{r o}$ & 51.5 \\
Rotor yoke thickness (mm) & $Y_{r t}$ & 7.75 \\
Airgap length (mm) & $g$ & 0.25 \\
Axial length $(\mathrm{mm})$ & $L_{a x}$ & 50 \\
Number of turns/coil & $N_{t}$ & 168 \\
Coil resistance $(\Omega)$ & $R_{c o i l}$ & 1.8 \\
Steel grade & - & NO20 \\
Rated speed (rpm) & $n$ & 9000 \\
Rated coil voltage (V) & $V_{r}$ & 800 \\
Rated coil current (A) & $I_{r}$ & 25 \\
The inertia $\left(\mathrm{Kg} . \mathrm{m}^{2}\right)$ & $J$ & 0.012 \\
Friction coefficient $(\mathrm{N} \cdot \mathrm{m} / \mathrm{rad} / \mathrm{s})$ & $B$ & 0.002 \\
\hline
\end{tabular}

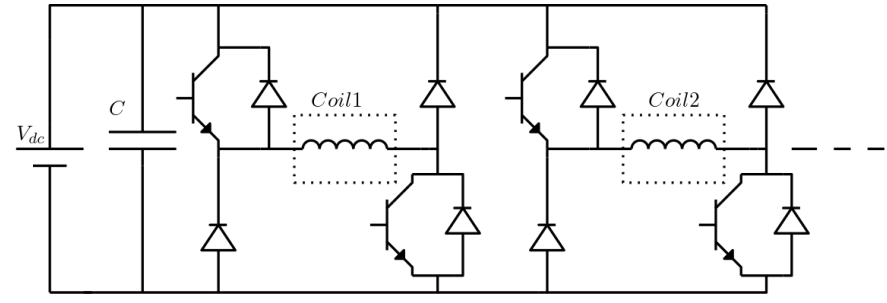

Fig. 2. SRM converter structure

$$
\begin{aligned}
v_{x} & =i_{x} R_{c o i l}+\frac{d \psi_{x}(\theta, i)}{d t} \\
w_{c x}(\theta, i) & =\int_{0}^{i} \psi_{x}(\theta, i) d i \\
T_{x}(\theta, i) & =\frac{\partial w_{c x}(\theta, i)}{\partial \theta}
\end{aligned}
$$

where, $v_{x}$ and $i_{x}$ are the voltage and the current of the coil $x, \psi_{x}(\theta, i)$ is the flux linkage of the coil $x, w_{c x}(\theta, i)$ is the co-energy of the coil $x, T_{x}(\theta, i)$ is the airgap torque generated by the coil $x$ and $\theta$ is the rotor position.

Each stator coil $x$ generates a torque pulse that can be calculated from (4). A continuous output torque can be obtained by proper application of current excitation at the moments of positive torque production and proper shifting of the current pulses of the coils. The total airgap torque can be calculated from (4).

$$
T_{e}(\theta)=\sum_{x=1}^{m} T_{x}(\theta, i)
$$

where, $T_{e}(\theta)$ is the total airgap torque as function in the rotor position $\theta, m$ is the number of the stator coils. The mechanical part of the machine is modelled with (5).

$$
T_{e}(\theta)=J \frac{d \omega}{d t}+B \omega+T_{l}
$$

where, $\omega$ is the angular speed of the machine, $T_{l}$ is the load torque, the other parameters are defined in TableI.

The torque ripple $\left(\hat{T}_{e}\right)$ can be calculated from (6).

$$
\hat{T}_{e}=100 *\left(\frac{\max \left(T_{e}(\theta)\right)-\min \left(T_{e}(\theta)\right)}{T_{l}}\right)
$$

Te winding losses $P_{w d g}$ can be calculated from (7).

$$
P_{w d g}=m I_{r m s}^{2} R_{c o i l}
$$

where, $I_{r m s}$ is the rms of the coil current waveform.

2) The power converter model: Fig. 2 shows the construction of the asymmetric H-bridge. Each module consists of two switches and two diodes. In the conventional driving method, a number of coils are connected together and supplied from one asymmetric H-bridge. In the modular techniques, each coil is supplied from one converter.

Since the DC-link voltage is $>650 \mathrm{~V}$, the switches and the diodes can be implemented either by Silicon (Si) or Silicon carbide (SiC) technology [6]. Due to the lower losses, the 
TABLE II

KEY PROPERTIES OF THE SEMICONDUCTOR DEVICES

\begin{tabular}{|c|c|c|}
\hline \multirow{2}{*}{ Property } & \multicolumn{2}{|c|}{ Value } \\
\cline { 2 - 3 } & Switch & Diode \\
\hline Rated voltage (V) & 1200 & 1200 \\
Continuous current rating (A) & 30 & 33 \\
Peak current rating $(\mathrm{A})$ & 80 & 80 \\
Rated junction temperature $\left({ }^{\circ} \mathrm{C}\right)$ & 150 & 175 \\
Junction to case thermal resistance $\left({ }^{\circ} \mathrm{C} / \mathrm{W}\right)$ & 1.1 & 0.85 \\
Drain to source resistance $\mid 25^{\circ} \mathrm{C}(\mathrm{m} \Omega)$ & 75 & - \\
The current rise time $(\mathrm{ns})$ & 9 & - \\
The current fall time $(\mathrm{ns})$ & 10 & - \\
Anode to cathode voltage drop $(\mathrm{V})$ & - & 1.5 \\
Reverse recovery charge $(\mathrm{nC})$ & - & 57 \\
\hline \multicolumn{2}{|c}{}
\end{tabular}

lower thermal resistance from the junction to the case and the capability to switch with high switching frequency, the $\mathrm{SiC}$ technology is chosen for the converter design in this paper.

The semiconductor devices selected for the switches and the diodes are C3M0075120J from Wolfspeed and LSIC2SD120C10 from Littlefuse respectively. The main specifications of these devices are listed in Table II.

For the efficiency and the cooling requirement comparison of the power converter for driving techniques, the power loss of the switches and the diodes should be calculated. (8) and (9) are used for switch and diode loss calculations respectively.

$$
\begin{aligned}
& \left\{\begin{array}{l}
P_{\text {cons }}=I_{\text {srms }}^{2} R_{d s} \\
P_{\text {son }}=V_{d c} f_{o} \sum_{n=1}^{n_{\text {son }}}\left(t_{\text {on }}(n) i_{\text {on }}(n)+Q_{r r}(n)\right) \\
P_{\text {soff }}=V_{d c} f_{o} \sum_{n=1}^{n_{\text {soff }}}\left(t_{\text {off }}(n) i_{\text {off }}(n)\right) \\
P_{\text {st }}=P_{\text {cons }}+P_{\text {son }}+P_{\text {soff }}
\end{array}\right. \\
& \begin{cases}P_{\text {cond }} & =f_{o} \int_{t}^{t+T_{o}} i_{d}(t) v_{d}(t) d t \\
P_{s d} & =0.25 V_{d c} f_{o} \sum_{n=1}^{n_{d o f f}} Q_{r r}(n) \\
P_{d t} & =P_{\text {cond }}+P_{s d}\end{cases}
\end{aligned}
$$

where, $P_{\text {cons }}, P_{\text {son }}, P_{\text {soff } f}, P_{s t}$ are the switch conduction, turn on, turn off and total losses respectively, $V_{d c}$ is the DC-link voltage, $f o$ is the fundamental frequency of the switch current waveform, $n_{\text {son }}$ and $n_{\text {soff } f}$ are the number of turn-on and turn-off transitions of the switch in one fundamental cycle respectively, $t_{o n}(n)$ and $t_{o f f}(n)$ are the turn-on and the turnoff time of the switch at the transition number $n, i_{o n}(n)$ and $i_{\text {off }}(n)$ are the switch current at the turn on and off instants respectively, $Q_{r r}(n)$ is the reverse recovery charge of the diode, $T_{o}=\frac{1}{f_{o}}, i_{d}(t)$ and $v_{d}(t)$ are the instantaneous current and voltage drop of the diode, $P_{c o n d}, P_{s d}, P_{d t}$ are the diode conduction, switching and total losses respectively.

Since the size of the DC-link capacitor $C$ determines the power density of the whole converter, The capacitance is calculated from (10) for all driving techniques.

$$
\begin{cases}C & =\frac{\Delta Q}{\Delta V} \\ \Delta Q & =\left.\int i_{c}(t)\right|_{\text {ch/disch }} d t\end{cases}
$$

where, $\Delta Q$ is the amount of charge that the capacitor gains or loses every switching cycle, $\Delta V$ is the peak to peak capacitor voltage ripple, $i_{c}(t)$ is the capacitor current during charging or discharging.

The capacitor is sized to have $\Delta V=1 \% V_{d c}$.

3) The controller: Different control structures can be adopted for the speed and/or the torque control of the SRM machine. In this paper, a cascaded speed-current control loops are adopted (See Fig. 1).

Both the speed and the current controllers have a proportional plus integral (PI) form. The current controller is designed to have an inner loop bandwidth of one tenth of the switching frequency so that the converter dynamics can be neglected. For a stable outer speed control loop, the inner current control loop should be much faster so that the bandwidth of the outer loop is set to one eighth of the inner loop.

The output of the speed controller (11) which sets the current reference $I^{*}$ for the inner loop is limited to the coil rated current $(25 \mathrm{~A})$ while, the output of the current controller (12) sets the average voltage of the pulses to be applied on the coil terminals. These pulses are generated by comparing the output of the current controller $\bar{v}_{x}$ to a sawtooth with the desired switching frequency $\left(f_{s}\right)$.

$$
\begin{gathered}
I^{*}=K_{p s}\left(\omega^{*}-\omega\right)+K_{I s} \int_{0}^{t}\left(\omega^{*}-\omega\right) d t \\
\bar{v}_{x}=K_{p i}\left(I^{*}-I_{x}\right)+K_{I i} \int_{0}^{t}\left(I^{*}-I_{x}\right) d t
\end{gathered}
$$

The switching frequency adopted in the simulations is 50 $\mathrm{kHz}$.

\section{B. SRM electromagnetic FEM model}

A 2-D electromagnetic FEM model is built for two purposes: the first one is to generate the finger prints (i.e. $\psi(\theta, i)$ ) of the 6/4 SRM machine for two diagonally opposite coils connected in series (the conventional driving method) and for a single coil with double the number of turns of the conventional case (the modular driving methods). These finger prints are necessary for the calculation of the instantaneous current and the torque in the dynamic simulation environment [7] (see (1)(3)).

Fig. 3 shows the fingerprint of the SRM machine considered for the case study in this paper (see Table I) for two coils in series. For one coil with the same number of turns, the flux linkage is almost half of that of the two coils in series. The finger print of one coil with double the number of turns is in Fig. 4.

The second purpose of the electromagnetic FEM model is to calculate the core losses of the SRM machine. Different kinds of flux density waveforms are existing in the different parts of the SRM core. All these waveforms are not only far from being sinusoidal but also have different frequencies in the different parts of the core. From part to part in the core, the flux density could be unipolar or DC-biased bipolar with multiple times of local flux slope reversal. 


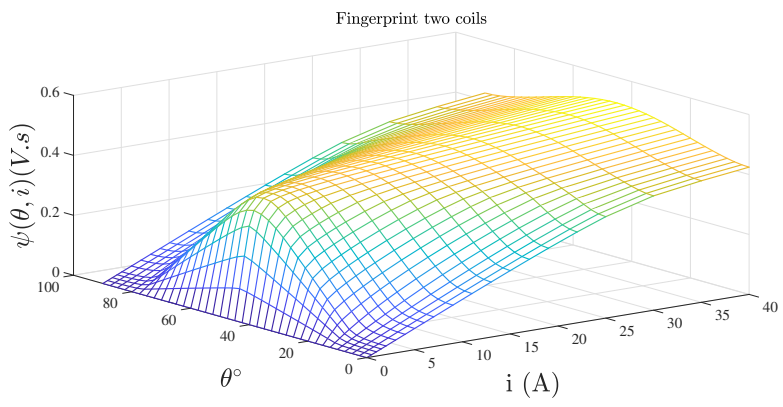

Fig. 3. SRM fingerprint for two coils in series with Ns turns each

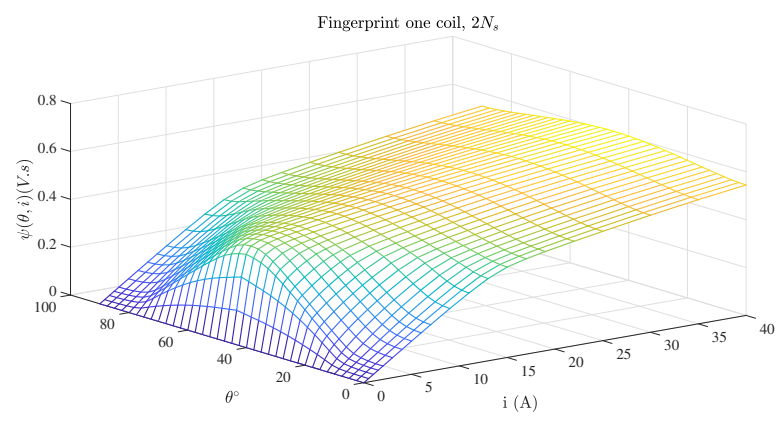

Fig. 4. SRM fingerprint one coil, $2 N_{s}$

To account for such complexity of the flux density waveform and variation from part to part in the core, the core is divided into small volumes in which the flux density waveform is computed and recorded by the FEM model and the losses are calculated using (13)-(15) .

Equation (13) gives the dynamic core loss component per $\mathrm{kg}$ while, (15) gives the hysteresis loss component per $\mathrm{kg}$ taking into consideration the different minor hysteresis loops resulting from different flux density waveforms [8].

The total core loss is computed by summing the loss components in the different small volumes and multiplying by the mass of the core.

$$
\left\{\begin{array}{l}
P_{\text {eddy }}=K_{f 1} f_{B} \int_{0}^{T_{B}}\left(\frac{d B}{d t}\right)^{2} d t \\
P_{\text {excess }}=k_{f 3} f_{B} \int_{0}^{T_{B}}\left(\sqrt{1+k_{f 4}\left|\frac{d B}{d t}\right|}-1\right)\left|\frac{d B}{d t}\right| \\
P_{d y}=P_{\text {eddy }}+P_{\text {excess }}
\end{array}\right.
$$

$K\left(B_{m}\right)=\left\{\begin{array}{l}0.4+\frac{0.65}{B_{m}} \sum_{i=1}^{n_{m}} \Delta B_{i} \rightarrow \text { unipolar flux density } \\ \frac{0.65}{B_{m}} \sum_{i=1}^{n_{m}} \Delta B_{i} \rightarrow \text { DC biased bipolar flux density }\end{array}\right.$

$$
P_{h}=K_{f 5} f_{B} B_{m}^{\alpha} K\left(B_{m}\right)
$$

where, $P_{\text {eddy }}, P_{\text {excess }}, P_{d y}, P_{h}$ are the eddy, excess, dynamic and hysteresis losses respectively, $K_{f 1}, K_{f 3}, K_{f 4}, K_{f 5}$, $\alpha$ are the core material loss coefficients, $B$ is the flux density, $f_{B}=\frac{1}{T_{B}}$ is the frequency of the flux density waveform, $n_{m}$ is the number of local slope reversal of the flux density (i.e. the minor loops), $\Delta B_{i}$ is the peak to peak flux density of the

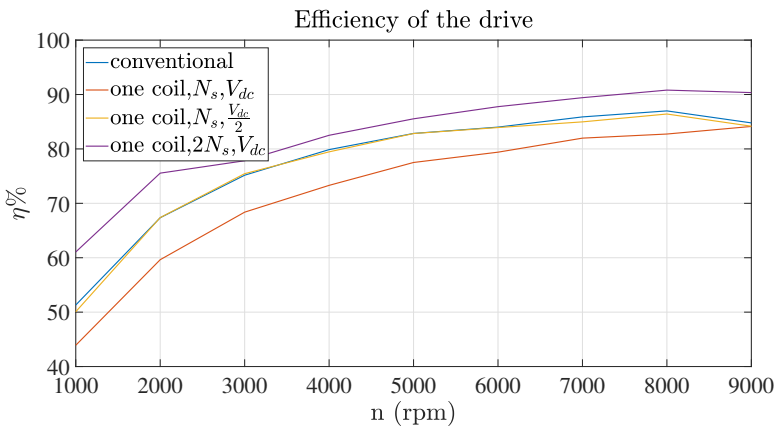

Fig. 5. The drive efficiency

minor loop, $B_{m}$ is the maximum value of the flux density waveform.

\section{Simulation RESULTS}

In this section, the drive efficiency and the torque ripples as the drive performance indices are evaluated and compared for a fixed load torque of 4.5 N.m and the speed range 1000-9000 $\mathrm{rpm}$ for the conventional and the modular driving techniques.

As the power converter density indices, the converter losses, the cooling requirement and the DC-link capacitance size are evaluated and compared as well.

\section{A. Drive performance comparison}

Fig. 5 shows the efficiency of the whole drive (the machine and the power converter losses are considered) for all the conventional and the modular driving techniques. All the driving techniques that maintain the number of turns per coil are achieving almost the same efficiency of $84.5 \%$ at the rated speed.

The driving method $\left(2 N_{s}, V_{d c}\right)$ achieves the highest global efficiency at any speed with an efficiency of $91 \%$ at the rated speed. This can be explained by inspecting Fig. 3 and Fig. 4. The flux linkage of the $\left(2 N_{s}, V_{d c}\right)$ method is higher than the conventional one at any current and position which means a higher winding inductance. This higher inductance smooths the winding current and results in a slower current rise and fall times. The smoother and slowly changing current means smaller winding rms current and losses and less on/off switching cycles during the conduction period of the coil which means smaller switching losses in the converter.

From Fig. 5, it can be seen that the efficiency of the conventional drive is almost the same as the efficiency of the modular drive that keeps the number of turns and reduces the voltage to half. The prospected higher current overshoot and more switching cycles per coil conduction period due to smaller damping and inductance are compensated by the smaller DC-link voltage resulting in almost the same efficiency of the drive.

This means that the modular driving techniques $\left(N_{S}, \frac{V_{d c}}{2}\right)$ and $\left(2 N_{S}, V_{d c}\right)$ are providing the inherent fault tolerance capability that the conventional method lacks and provides the same drive efficiency or higher. 


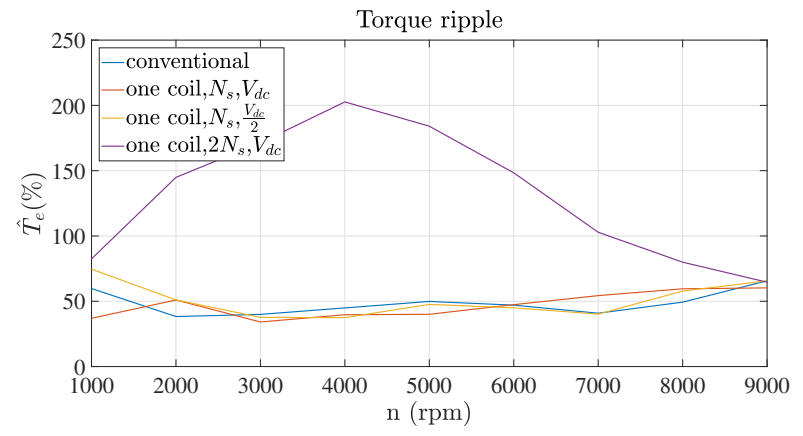

Fig. 6. The torque ripple
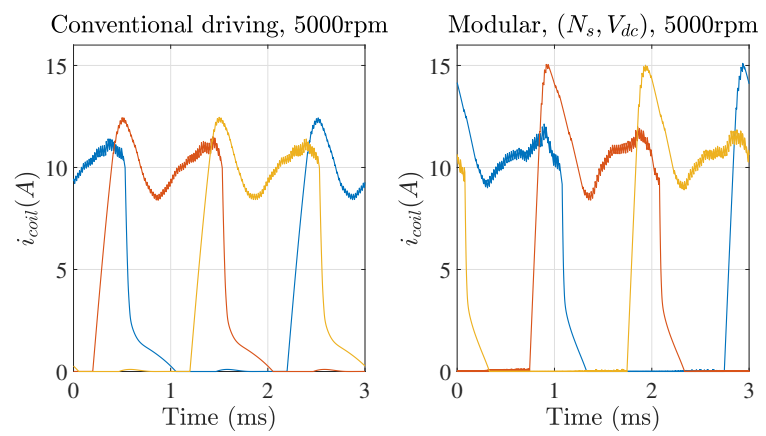

Fig. 7. The coil current for conventional driving (left), and modular $\left(N_{s}, V_{d c}\right)$ at 5000rpm

The torque ripple is calculated as the percentage of the peak to peak airgap torque to the load torque (note that the total torque includes a friction term $B \omega$, see (6)). The figure of the torque ripple for all the driving techniques is depicted in Fig. 6. It can be noticed that the average torque ripple is almost the same $(48.5 \%)$ for all the driving techniques except the one with double of the coil turns, and this can be explained by the higher coil inductance and longer current rise and fall time of that driving technique. This longer transient time of the current means longer phase conduction during negative torque production which means higher torque ripple. This can be mitigated by adopting instantaneous torque control methods [4].

Fig. 7 depicts the current waveform of the conventional and the modular method $\left(N_{s}, V_{d c}\right)$. Fig. 8 shows the current waveform for the modular techniques $\left(N_{s}, \frac{V_{d c}}{2}\right),\left(2 N_{s}, V_{d c}\right)$. It can be seen the long rise and fall times of the technique $\left(2 N_{s}, V_{d c}\right)$ explained earlier.

\section{B. Converter power density}

The power density of the converter is determined by the power losses that results in the maximum allowed junction temperature. The maximum allowed junction temperature of the devices selected for the case study in this paper is considered $125^{\circ} \mathrm{C}$ to leave a $25^{\circ} \mathrm{C}$ margin (see TableII).

Considering that the thermal pads of the selected switch and diode are the drain and the cathode of these devices respectively, whether the converter modules are all implemented on
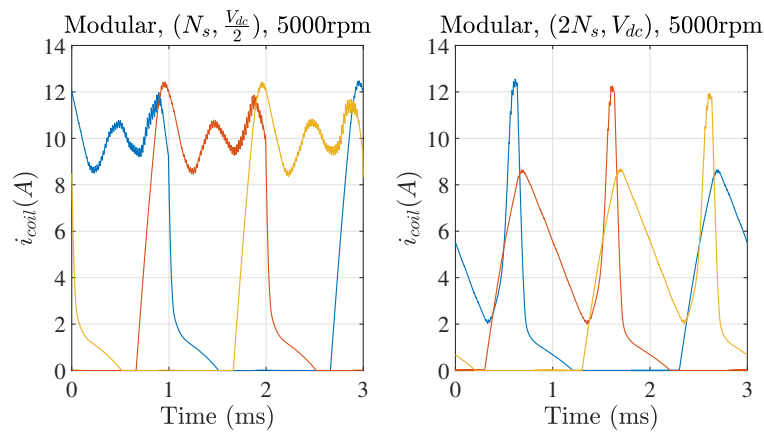

Fig. 8. The coil current for modular method $\left(N_{s}, \frac{V_{d c}}{2}\right)$ (left), and modular $\left(2 N_{s}, V_{d c}\right)$ (right) at $5000 \mathrm{rpm}$

TABLE III

MAXIMUM POWER LOSSES OF THE CONVERTER DEVICES

\begin{tabular}{|c|c|c|c|}
\hline \multirow{2}{*}{ Driving technique } & \multicolumn{2}{|c|}{ Maximum device losses } & \multirow{2}{*}{$\mathbf{R}_{c a}\left({ }^{\circ} \mathbf{C} / \mathbf{W}\right)$} \\
\cline { 2 - 3 } & Switch & Diode & \\
\hline Conventional & 15.9 & 3.2 & 4.3 \\
Modular $N_{s}, V_{d c}$ & 18.2 & 3.7 & 3.6 \\
Modular $N_{s}, \frac{V_{d c}}{2}$ & 8.2 & 3.2 & 9.3 \\
Modular $2 N_{s}, V_{d c}$ & 6.5 & 1.64 & 11.9 \\
\hline
\end{tabular}

the same PCB (the conventional driving) or a separate PCB for each converter module, the heat generated by the lower devices in the converter are expected not to be coupled with each other or with the upper devices (see Fig. 2). So, the junction temperature of the lower devices would be higher than the upper ones and dependant only on the thermal resistance from the junction to the cooling ambient, the ambient temperature and the power losses of the individual switch or diode.

Table III lists the maximum switch and diode losses in the speed range $1000-9000 \mathrm{rpm}$ computed at $125^{\circ} \mathrm{C}$ junction temperature.

From Table III, the modular method with $\left(N_{s}, V_{d c}\right)$ results in the highest device losses due to the higher switching losses resulting from higher $V_{d c}$ compared to the technique $\left(N_{s}, \frac{V_{d c}}{2}\right)$ and the lower coil inductance compared to $\left(2 N_{s}, V_{d c}\right)$ resulting in faster coil current rise and fall times and hence more on/off switching cycles during the coil conduction period.

The size of the heatsink needed for cooling can be estimated from its thermal resistance $\left(R_{c a}\left({ }^{\circ} \mathrm{C} / \mathrm{W}\right)\right)$. The smaller the heatsink thermal resistance the bigger its size. The maximum heatsink thermal resistance can be estimated from the maximum temperature difference between the junction and the ambient $(\Delta T)$ and the power losses occurring in the junction at that difference $P_{\text {device }}(16)$.

$$
R_{c a}=\frac{\Delta T}{P_{\text {device }}}-R_{j c}
$$

where, $R_{j c}$ is the thermal resistance from junction to case of the device.

Assuming an ambient temperature of $40^{\circ} \mathrm{C}$ and considering the switch power losses for the calculation of the heatsink thermal resistance as its power losses are much higher than the diode due to the higher switching losses and voltage drop, 


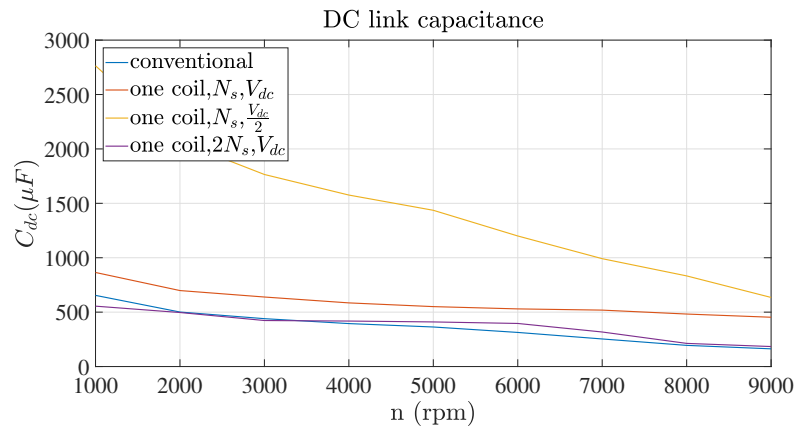

Fig. 9. The DC link capacitance to have $1 \%$ peak to peak ripple

Table III contains the maximum thermal resistance of the heatsink needed for each driving technique.

The modular driving technique with $\left(2 N_{s}, V_{d c}\right)$ requires the smallest heatsink size even in comparison to the conventional driving due to its lowest switch losses resulting from the perfect current smoothing (i.e. the high inductance and low current ripples), this smaller heatsink size compensates the higher number of semiconductor component count in the modular approach.

Note from (16), a smaller heatsink would be needed for $\mathrm{SiC}$ devices as their thermal conductivity is almost three times higher thermal conductivity than the Si material.

Fig. 9 shows the required DC-link capacitance versus the speed of the motor. Unlike the conventional machines where the DC-link capacitance is almost independent of the motor speed, for the SRM machine the smaller the minimum drive speed the bigger the DC-link capacitance needed. This can be explained by inspecting Fig. 10 that represents the spectrum of the DC-link capacitor current at $9000 \mathrm{rpm}$ generated for the conventional driving case, a significant low frequency component exists in the current. This frequency is equivalent to three times the coil current frequency for the 6/4 SRM machines as three symmetrical current waveforms add up to form the DC-link current waveform. This low frequency current results in a big amount of charge that needs to be added to and removed from the capacitor each cycle. The smaller the speed, the smaller the frequency and hence the bigger the DC-link capacitance.

It is interesting also to notice the other DC-link current components having frequencies at the sidebands of the switching frequency $\left(f_{s}\right)$ like the conventional machines in this aspect. This means the higher the switching frequency, the lower the amount of DC-link voltage ripple contribution for these components. This high switching frequency is made possible by the $\mathrm{SiC}$ technology adopted for the converter design.

The DC-link capacitance needed for the $\left(N_{s}, \frac{V_{d c}}{2}\right)$ is almost four times that needed for the conventional technique because of the lower DC-link voltage.

\section{CONCLUSION}

In this paper, three modular driving techniques are compared to the conventional phase connection technique. These

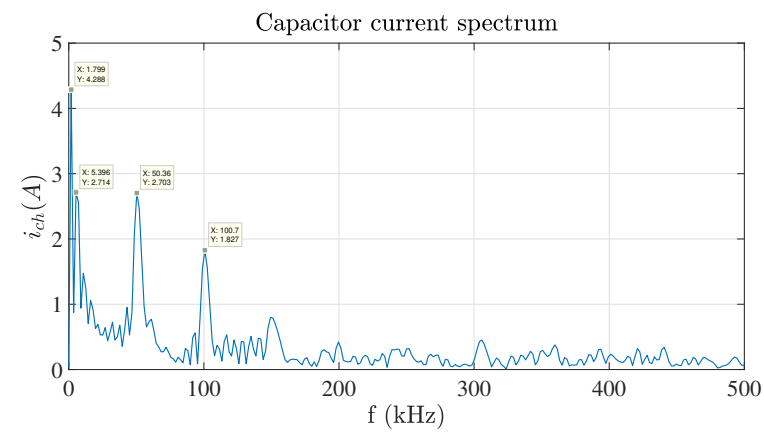

Fig. 10. Capacitor current spectrum, conventional, $9000 \mathrm{rpm}$

techniques are either keeping the DC-link voltage or the coil number of turns the same. The modular $\left(2 N_{s}, V_{d c}\right)$ technique results in the highest drive efficiency, smallest DClink capacitance, smallest converter cooling requirement but produces the highest torque and the higher number of turns results in a heavier drive. The modular $\left(N_{s}, \frac{V_{d c}}{2}\right)$ results in the same drive efficiency as the conventional one, a small torque ripple, possibility to select lower voltage rated devices $<650 \mathrm{~V}$ which enables the use of the GaN technology as well but requires the bulkiest DC-link capacitance and a little higher cooling requirement than $\left(2 N_{s}, V_{d c}\right)$. For all the modular driving techniques, the DC-link capacitance can be distributed among the modules and reduced in size by shifting the current pulses of the windings having the same reluctance path to the rotor.

\section{REFERENCES}

[1] C. Gan, J. Wu, Y. Hu, S. Yang, W. Cao, and J. M. Guerrero, "New Integrated Multilevel Converter for Switched Reluctance Motor Drives in Plug-in Hybrid Electric Vehicles with Flexible Energy Conversion," IEEE Transactions on Power Electronics, vol. 32, no. 5, pp. 3754-3766, 2017.

[2] H. Li, B. Bilgin, and A. Emadi, "An Improved Torque Sharing Function for Torque Ripple Reduction in Switched Reluctance Machines," IEEE Transactions on Power Electronics, vol. 34, no. 2, pp. 1635-1644, 2019.

[3] K. M. Rahman, B. Fahimi, G. Suresh, A. V. Rajarathnam, and M. Ehsani, "Advantages of switched reluctance motor applications to EV and HEV: design and control issues," IEEE Transactions on Industry Applications, vol. 36, no. 1, pp. 111-121, 2000 .

[4] J. Ye, B. Bilgin, and A. Emadi, "An extended-speed low-ripple torque control of switched reluctance motor drives," IEEE Transactions on Power Electronics, vol. 30, no. 3, pp. 1457-1470, 2015.

[5] M. D. Hennen, M. Niessen, C. Heyers, H. J. Brauer, and R. W. De Doncker, "Development and control of an integrated and distributed inverter for a fault tolerant five-phase switched reluctance traction drive," IEEE Transactions on Power Electronics, vol. 27, no. 2, pp. 547-554, 2012.

[6] K. Shirabe, M. Swamy, J. K. Kang, M. Hisatsune, Y. Wu, D. Kebort, and J. Honea, "Advantages of high frequency PWM in AC motor drive applications," 2012 IEEE Energy Conversion Congress and Exposition, ECCE 2012, pp. 2977-2984, 2012.

[7] N. C. Lenin and R. Arumugam, "Analysis and characterization of linear switched reluctance motors: Static, dynamic, frequency spectrum and thermal analyses," Digests of the 2010 14th Biennial IEEE Conference on Electromagnetic Field Computation, CEFC 2010, vol. 41, no. 4, pp. 1306-1320, 2010.

[8] L. Chen, H. Chen, and W. Yan, "A fast iron loss calculation model for switched reluctance motors," IET Electric Power Applications, vol. 11, no. 3, pp. 478-486, 2017. 